\title{
ANALISIS KEBUTUHAN BANDWIDTH DENGAN MODEL SHARING SYSTEM PADA MIKROTIK ROUTERBOARD 450G DI JARINGAN OFFICE STTA
}

\author{
Mardiana Irawaty $^{1}$, Ferry Mulyawan ${ }^{2}$, Yenni Astuti ${ }^{3}$ \\ ${ }^{1,2}$ Prodi Teknik Informatika, ${ }^{3}$ Prodi Teknik Elektro \\ Sekolah Tinggi Teknologi Adisutjipto Yogyakarta \\ Jalan Janti, Blok-R Lanud Adisucipto, Yogyakarta \\ ${ }^{2}$ ferrymulyawan11@gmail.com
}

\begin{abstract}
The limitations between the amount of bandwidth and users can make the internet slow. Observing the flow of data on the internet network is one way to identify the bandwidth requirements which used on the STTA office network. This thesis analyzes the data traffic with sharing system model. The observed data is in the category of elastic flow rate, i.e: TCP (Transmission Control Protocol). The traffic data is converted to a measured data graph and then analyzed by traffic load, throughput, and flow of loss parameters. The highest observation value of traffic load is 0.37, Throughput of $9.3 \mathrm{Mbps}$ (93\%), and the flow of loss of $23 \%$. From the results of the research, it can be concluded that in general internet network at STTA office is in good category.
\end{abstract}

Keywords : Bandwidth, Sharing System, Traffic Load, Throughput, Flow of loss.

\section{Pendahuluan}

Dalam sebuah jaringan komputer, bandwidth adalah sumber daya yang terbatas. Oleh karena itu, penggunaannya haruslah dikelola dengan baik agar dapat menjamin kualitas layanan (QoS) dalam jaringan internet [1]. Permasalahan yang sering dihadapi adalah akses internet yang lambat, hal ini dikarenakan adanya kesenjangan antara jumlah bandwidth dengan jumlah penggunanya.

Jaringan Internet STTA juga semakin berkembang dalam hal jumlah dan kepadatan. Peningkatan ini akan lebih baik bila diiringi dengan monitoring bandwidth, khususnya yang berkaitan dengan bidang teletraffic. Tujuannya tentu saja untuk mendapatkan gambaran yang berupa pemodelan, mengenai kondisi jaringan Internet, khususnya aliran data.

Lebih lanjut, gambaran/pemodelan tersebut dapat dijadikan bahan pengambilan kebijakan yang berkaitan dengan Teknologi dan Informasi di office STTA. Berdasarkan pada latar belakang masalah yang telah dipaparkan di atas, maka penulis mengambil judul penelitian "Analisis Kebutuhan Bandwidth dengan Model Sharing system pada Mikrotik Routerboard 450G di Jaringan Office STTA".

\section{Metodologi Penelitian}

Penelitian ini dilakukan di kampus Sekolah Tinggi Teknologi Adisutjipto (STTA) Yogyakarta. Lamanya waktu pelaksanan penelitian adalah satu bulan, meliputi pengumpulan data, pemodelan sistem, analisis sistem, serta pembuatan laporan penelitian. 
Tahapan penelitian yang dilaksanakan, sebagai berikut:

\section{Studi Literatur.}

Pada tahap ini, dilakukan pembelajaran dari referensi-referensi yang berkaitan dengan topik penelitian, seperti buku, jurnal, serta sumber-sumber lain. Buku dan jurnal dapat berupa online maupun cetak.

\section{Pengumpulan Data}

Pada tahap ini, dilakukan pengumpulan data aliran Internet yang ada di Office STTA Yogyakarta. Pengumpulan data dilakukan pada jam kerja, yakni ketika jaringan banyak digunakan, baik untuk kepentingan mahasiswa, karyawan, maupun dosen STTA.

\section{Analisis}

Pada tahap ini, dilakukan analisis terhadap data yang telah diperoleh. Analisis meliputi pemodelan, serta perhitungan kuantitatif untuk mendapatkan kesimpulan berupa kelaikan kualitas layanan pada jaringan office STTA.

\subsection{Peralatan dan Bahan}

Dalam penelitian ini, alat dan bahan yang digunakan sebagai berikut:

1. Laptop Lenovo B490 dengan spesifikasi:Prosessor Intel ${ }^{\circledR}$ Core $^{\mathrm{TM}} \mathrm{i} 3-3110 \mathrm{M}(2.4$ GHz), RAM 2 GB DDR3, Harddisk 500 GB.

2. Perangkat lunak TORCH yang dapat memunculkan data trafik melalui tampilan website.

\subsection{Prinsip Kerja}

Penelitian ini menganalisis data trafik Internet office di kampus Sekolah Tinggi Teknologi Adisutjipto (STTA) Yogyakarta pada kategori level aliran data TCP dengan model sharing system yang berupa trafik elastic. Pada pemodelan sharing system, parameter trafik yang diamati adalah proses kedatangan aliran $(\lambda)$, yakni pada saat aliran baru datang, serta distribusi ukuran aliran. Dalam hal ini tidak ada aliran yang ditolak. Selain itu laju layanan $(\mu)$ disesuaikan dengan kapasitas sambungan dan rerata ukuran aliran. Adaptasi atas laju transmisi berlangsung secara cepat dan sambungan digunakan bersama-sama oleh pengguna.

\subsection{Diagram Alir Penelitian}

Diagram alir penelitian dapat dilihat pada Gambar 1. Pada diagram tersebut, jalannya penelitian diawali dengan studi pustaka atau mencari sumber pustaka yang dapat dijadikan acuan, baik dalam pembuatan model maupun analisis. Kemudian, diikuti dengan pengumpulan data yang nantinya akan dilakukan analisis terhadapnya. Setelah analisis dianggap valid, laporan disusun sesuai hasil penelitian. Namun jika analisis belum dapat dianggap valid, analisis data akan kembali dikerjakan.

Alur jalannya penelitian dari "Analisis Kebutuhan Bandwidth dengan Model Sharing System pada Mikrotik Routerboard 450G di Jaringan Office STTA", sebagai berikut. Pertama melakukan pembelajaran dari referensi-referensi yang berkaitan dengan topik penelitian, seperti buku jurnal, serta sumber-sumber lain. Buku dan jurnal dapat berupa online maupun cetak. Kedua pada tahap ini dilakukan pengumpulan data aliran Internet yang ada di STTA pada jam kerja dengan menggunakan aplikasi TORCH yang dapat memunculkan data trafik. Ketiga mengarah ke Pemodelan dimana akan dibuat rata-rata seperti, grafik hasil dari pengamatan selama satu bulan dan dengan parameter beban trafik (traffic load), throughput, dan aliran loss yang akan digunakan. Keempat pada tahap validasi, apakah sudah sesuai dengan metode yang diambil. Namun jika analisis belum dianggap valid, analisis data 
akan kembali dikerjakan. Kelima menganalisis model dari trafik pada kategori level aliran data. Dalam hal ini level, aliran dapat diklasifikasikan menjadi dua macam, yang pertama adalah aliran elastic menggunakan TCP (Transmission Control Protocol). Keenam, yaitu mencatat hasil dari analisis pemodelan setelah itu, masuk pada tahap ketujuh yaitu menarik kesimpulan dari hasil analisis. Kedelapan membuat laporan dari hasil pengamatan selama satu bulan dengan metode sharing dan parameter dari hasil data TORCH di UPT TIK Internet STTA dan sesuai dengan metode sharing pada trafik aliran data.

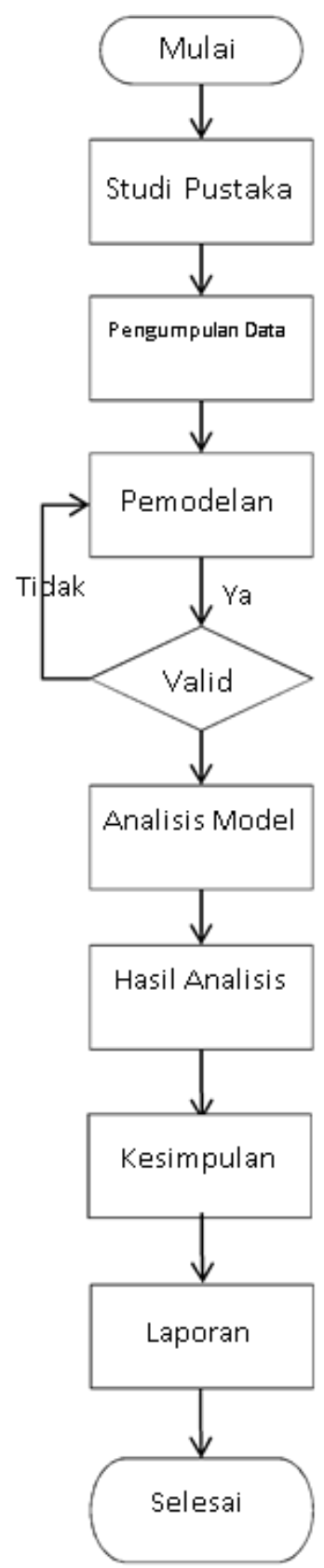

Gambar 1. Diagram Alir Jalannya Penelitian

\section{$3 \quad$ Hasil Pengamatan dan Pembahasan}

3.1 Grafik Rata-rata Tx dan Rx

Setelah dilakukan pencatatan hasil, data setiap pengujian 20 kali dikelompokkan berdasarkan trafik aliran elastik TCP. Pengukuran dilakukan dengan variasi kecepatan laju 
kedatangan dan pelayanan bandwidth yang digunakan, agar paket data yang melewati sebuah jaringan dari client ke router (mikrotik) dapat terpantau. Hasil akan membentuk sebuah grafik pada penelitian tersebut. Hasil pengamatan Grafik rata-rata selama 20 hari terdiri dari laju trafik (Mbps) Tx, Rx, dan Packet data (pps) Tx, Rx. Gambar 2 dan 3 adalah salah satu contoh data dan grafik data rata-rata prodi TP.

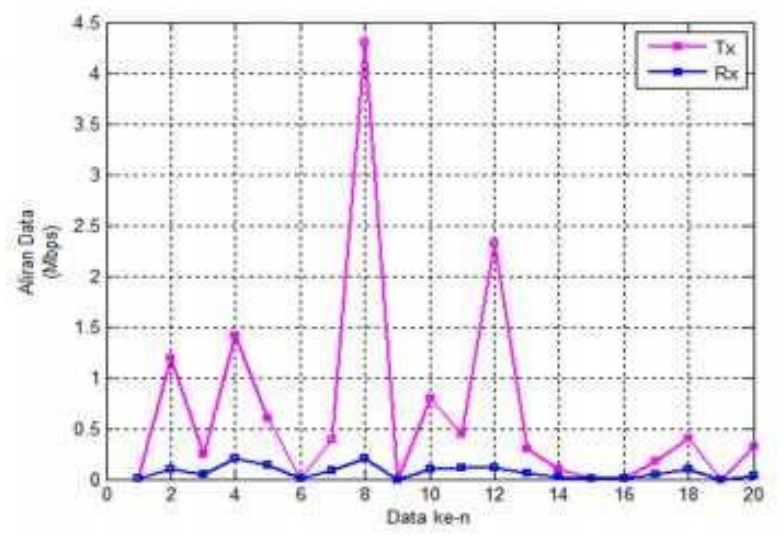

Gambar 2. Laju trafik rata-rata prodi TP selama 20 hari

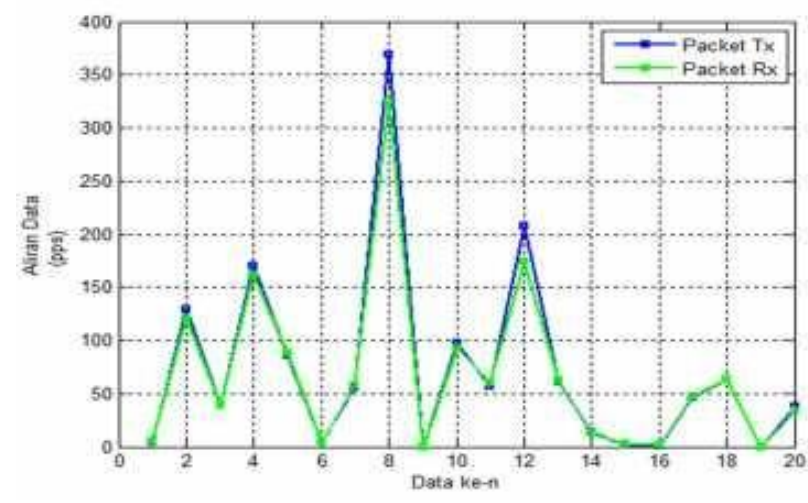

Gambar 3. Paket data rata-rata prodi TP selama 20 hari

Dari hasil pengamatan laju trafik dan packet data, terlihat bahwa Tx nya lebih besar dari pada Rx, hal ini di sebabkan karena Tx adalah laju data atau jumlah packet yang di kirim dari mikrotik. Sedangkan Rx adalah laju data atau jumlah packet yang di minta dari mikrotik. Permintaan dari mikrotik merupakan permintaan yang berasal dari berbagai client yang ingin mengakses server. Skema mikrotik, client, server dapat di lihat pada gambar 4.

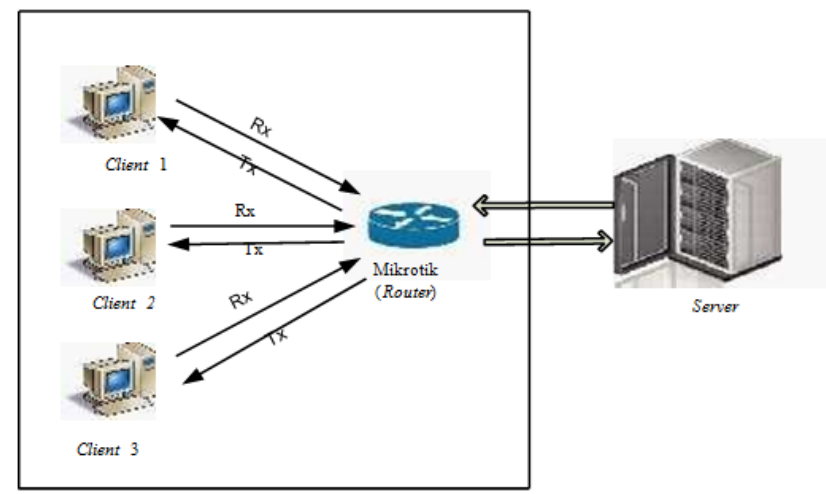

Gambar 4. Skema mikrotik, client, server 
Pengamatan dan pengukuran pada jaringan Internet di office STTA yang menggunakan penyambungan paket dan berbasis TCP/IP, telah membuktikan bahwa banyak sekali variasi yang ada. Variasi yang paling dasar adalah pengamatan pada level paket. Artinya trafik elastik yang sedang berada di aliran data Internet diamati sebagai suatu paket yang sedang bergerak. Data yang dipakai dalam penelitian tugas akhir ini adalah data kuantitatif.

Pada pengumpulan data pengamatan pada lima prodi, akan menunjukkan berbagai aliran trafik yang nantinya akan diambil dan di filter berdasarkan aliran elastic (TCP) dengan koneksi Internet yang terhubung ke laptop. Sebelum mengukur dan monitoring laju kecepatan dan paket rata-rata di aliran TCP diambil, waktu yang diperlukan selama 60 menit adalah tiap pukul 10 - 11 pagi dalam pengujian satu bulan hari kerja di STTA. Selama pengujiannya, aliran data trafik tersebut nantinya akan tercatat dan tersimpan otomatis pada aplikasi TORCH. Selanjutnya, berbagai jenis data aliran trafik tersebut diekspor kedalam data pengolah data. Dengan tujuan untuk memudahkan dalam filter trafik data TCP per hari selama satu jam. Pada Tabel 1, ditunjukkan rata-rata dari 20 data pengujian yang diamati pada salah satu prodi sesuai dengan analisis untuk menghasilkan suatu informasi berupa hasil analisis jaringan di Internet.

Tabel 1. Banyak rata-rata data pada Prodi TP

\begin{tabular}{|c|c|c|c|c|}
\hline \multicolumn{5}{|c|}{ Data rata-rata TP } \\
\hline Hari & Tx (bps) & $\mathrm{Rx}$ (bps) & Paket Tx & Paket $\mathrm{Rx}$ \\
\hline 1 & $5.773,33$ & $5.958,86$ & 4,00 & 4,71 \\
\hline 2 & $1.196 .856,29$ & $104.048,86$ & 128,86 & 121,13 \\
\hline 3 & $247.685,71$ & $52.379,29$ & 39,23 & 39,05 \\
\hline 4 & $1.415 .924,28$ & $200.215,31$ & 170,17 & 161,41 \\
\hline 5 & $599.233,40$ & $136.481,54$ & 85,51 & 87,88 \\
\hline 6 & $11.301,78$ & $4.340,00$ & 4,44 & 4,67 \\
\hline 7 & $393.435,54$ & $84.720,31$ & 55,15 & 57,98 \\
\hline 8 & $4.292 .048,53$ & $201.600,40$ & 369,02 & 324,45 \\
\hline 9 & 0 & 0 & 0 & 0 \\
\hline 10 & $797.186,93$ & $104.654,53$ & 97,17 & 93,02 \\
\hline 11 & $440.655,50$ & $106.528,50$ & 57,13 & 60,06 \\
\hline 12 & $2.327 .079,27$ & $111.379,93$ & 207,96 & 174,09 \\
\hline 13 & $293.873,47$ & $62.588,21$ & 61,32 & 62,66 \\
\hline 14 & $93.147,47$ & $25.117,07$ & 13,23 & 12,37 \\
\hline 15 & $3.116,80$ & $4.448,00$ & 2,00 & 3,00 \\
\hline 16 & $3.214,00$ & $2.578,00$ & 0,50 & 1,25 \\
\hline 17 & $172.268,85$ & $39.612,12$ & 46,76 & 47,79 \\
\hline 18 & $404.628,00$ & $98.578,33$ & 63,54 & 63,29 \\
\hline 19 & 0 & 0 & 0 & 0 \\
\hline 20 & $324.054,52$ & $31.350,81$ & 37,63 & 33,37 \\
\hline Rata- rata & $651.074,18$ & $68.829,00$ & 72,18 & 67,61 \\
\hline
\end{tabular}




\subsection{Laju Kedatangan $(\lambda)$}

Laju kedatangan biasanya dinotasikan dengan lambda $(\lambda)=$ (Tingkat kedatangan rata-rata laju trafik /unit waktu). Semua trafik yang datang dengan Rx rata-rata kedatangan $\lambda$ akan dilayani oleh sejumlah router. Dalam hal ini fungsi peluang Poisson digunakan untuk menggambarkan tingkat kedatangan dengan asumsi bahwa jumlah kedatangan acak. Kedatanganya dianggap sebagai kedatangan yang acak bila kedatangan tersebut tidak terkait satu sama lain dan laju kedatangan trafik ke dalam sistem selalu menurut proses Poisson, yaitu banyaknya trafik yang datang sampai pada waktu tertentu mempunyai distribusi Poisson. Hal ini benar apabila kedatangan trafik secara acak pada kecepatan kedatangan ratarata tertentu. Pada Tabel 2 adalah nilai laju kedatangan rata-rata 5 prodi.

Tabel 2. Laju kedatangan rata-rata

\begin{tabular}{|c|c|c|c|}
\hline \multirow{2}{*}{ No. } & \multirow{2}{*}{ Prodi } & \multicolumn{2}{|c|}{ Laju kedatangan $(\lambda)$} \\
\cline { 3 - 4 } & & Trafik & Paket \\
\hline 1 & TP & $69 \mathrm{kbps}$ & $67,61 \mathrm{pps}$ \\
\hline 2 & TM & $801 \mathrm{kbps}$ & $268,29 \mathrm{pps}$ \\
\hline 3 & TI & $111 \mathrm{kbps}$ & $113,23 \mathrm{pps}$ \\
\hline 4 & TF & $152 \mathrm{kbps}$ & $169,31 \mathrm{pps}$ \\
\hline 5 & TE & $154 \mathrm{kbps}$ & $131,49 \mathrm{pps}$ \\
\hline
\end{tabular}

\subsection{Laju Pelayanan $(\boldsymbol{\mu})$}

Laju pelayanan biasanya dinotasikan dengan miu $(\mu)=$ (Tingkat pelayanan ratarata/unit waktu). Laju pelayanan Tx rata-rata $\mu$ adalah distribusi waktu pelayanan yang dibutuhkan untuk melayani pelanggan. Biasanya waktu pelayanan ini diasumsikan menggunakan distribusi probabilitas. Waktu yang diperlukan untuk pelayanan dimulai hingga selesai disebut waktu pelayanan, yakni ditentukan berdasarkan sampel dari keadaan sebenarnya. Dalam keadaan tertentu, dapat berupa distribusi Erlang, Eksponensial, Uniform, dan lain-lain. Tabel 3 adalah nilai laju pelayanan rata-rata 5 prodi.

Tabel 3. Laju pelayanan rata-rata

\begin{tabular}{|c|c|c|c|}
\hline \multirow{2}{*}{ No. } & \multirow{2}{*}{ Prodi } & \multicolumn{2}{|c|}{ Laju Pelayanan $(\mu)$} \\
\cline { 3 - 4 } & & Trafik & Paket \\
\hline 1 & TP & $0,651 \mathrm{Mbps}$ & $72,18 \mathrm{pps}$ \\
\hline 2 & TM & $2,174 \mathrm{Mbps}$ & $270,14 \mathrm{pps}$ \\
\hline 3 & TI & $1,473 \mathrm{Mbps}$ & $145,39 \mathrm{pps}$ \\
\hline 4 & TF & $1,892 \mathrm{Mbps}$ & $191,03 \mathrm{pps}$ \\
\hline 5 & TE & $1,369 \mathrm{Mbps}$ & $141,69 \mathrm{pps}$ \\
\hline
\end{tabular}

\subsection{Traffic Load Setiap Prodi}

Definisi traffic load $(\rho)$ merupakan perbandingan antara laju kedatangan/ arrival rate $(\lambda)$ dengan waktu pelayanan (service rate) $\mu=\mathrm{C} / \mathrm{L}$, dengan:

1. Costumer $=$ paket

$\lambda=$ Laju kedatangan paket (Tingkat kedatangan rata-rata paket/unit waktu)

$\mathrm{L}=$ Panjang paket rata-rata (data unit)

2. Server $=$ Link, tempat menunggu $=$ Buffer

$\mathrm{C}=$ Kecepatan link (data unit/unit waktu)

Waktu pelayanan $=$ waktu transmisi paket rata-rata $($ packet transmission time $)$

$1 / \mu=\mathrm{L} / \mathrm{C}=$ waktu transmisi paket rata-rata 


$$
\rho=\frac{\lambda}{\mu}
$$

Keterangan:

$$
\begin{aligned}
& \rho=\text { Traffic Load } \\
& \lambda=\text { Laju kedatangan } \\
& \mu=\text { Laju pelayanan (service rate) }
\end{aligned}
$$

A. Traffic load pada Prodi TP

Diketahui :

Tx rata-rata $(\lambda)=68.829,00 \mathrm{bps}=69 \mathrm{kbps}$

Rx rata-rata $(\mu)=651.074,18$ bps $=0,651 \mathrm{Mbps}$

Maka,

$$
\rho=\frac{69 \times 10^{3}}{0,651 \times 10^{6}}=0,11
$$

B. Traffic load pada Prodi TM

Diketahui :

Tx rata-rata $(\lambda)=801.458,99 \mathrm{bps}=801 \mathrm{kbps}$

$\operatorname{Rx}$ rata-rata $(\mu)=2.173 .812,26$ bps $=2,174 \mathrm{Mbps}$

Maka,

$$
\rho=\frac{801 \times 10^{3}}{2,174 \times 10^{6}}=0,37
$$

C. Traffic load pada Prodi TI

Diketahui :

Tx rata-rata $(\lambda)=110.724,67 \mathrm{bps}=111 \mathrm{kbps}$

$\operatorname{Rx}$ rata-rata $(\mu)=1.473 .261,07 \mathrm{bps}=1,473 \mathrm{Mbps}$

Maka,

$$
\rho=\frac{111 \times 10^{3}}{1,473 \times 10^{6}}=0,08
$$

D. Traffic load pada Prodi TF

Diketahui :

Tx rata-rata $(\lambda)=152.377,29 \mathrm{bps}=152 \mathrm{kbps}$

$\operatorname{Rx}$ rata-rata $(\mu)=1.891 .940,34$ bps $=1,892 \mathrm{Mbps}$

Maka,

$$
\rho=\frac{152 \times 10^{3}}{1,892 \times 10^{6}}=0,08
$$

E. Traffic load pada Prodi TE

Diketahui :

Tx rata-rata $(\lambda)=153.933,43 \mathrm{bps}=154 \mathrm{kbps}$

$\operatorname{Rx}$ rata-rata $(\mu)=1.368 .879,80 \mathrm{bps}=1,369 \mathrm{Mbps}$

Maka,

$$
\rho=\frac{154 \times 10^{3}}{1,369 \times 10^{6}}=0,11
$$




\subsection{Traffic Load}

Yaitu kecepatan (rate) transfer data efektif, yang diukur dalam bps. Throughput merupakan jumlah total kedatangan paket yang sukses yang diamati pada destination selama interval waktu tertentu dibagi oleh durasi interval waktu tersebut. Tabel 4 merupakan tabel kategori throughput, Sedangkan Tabel 5 merupakan Kategori Aliran Loss.

Tabel 4. Kategori Throughput

\begin{tabular}{|l|c|c|}
\hline Kategori Throughput & Throughput & Indeks \\
\hline Sangat Bagus & $100 \%$ & 4 \\
\hline Bagus & $75 \%$ & 3 \\
\hline Sedang & $50 \%$ & 2 \\
\hline Jelek & $<25 \%$ & 1 \\
\hline
\end{tabular}

Tabel 5. Kategori Aliran Loss

\begin{tabular}{|l|c|c|}
\hline Kategori Aliran Loss & Aliran Loss & Indeks \\
\hline Sangat Bagus & $0-3 \%$ & 4 \\
\hline Bagus & $4-15 \%$ & 3 \\
\hline Sedang & $16-25 \%$ & 2 \\
\hline Jelek & $>25 \%$ & 1 \\
\hline
\end{tabular}

Throughput dalam model sistem sharing dapat diperoleh menggunakan persamaan 2.

$$
\theta=\frac{r \times n(1-\rho)}{P W+n(1-\rho)}
$$

Dengan

$$
\begin{array}{ll}
\theta & =\text { throughput } \\
r & =\text { kecepatan akses link untuk aliran (unit data per unit waktu) } \\
n & =\text { banyak server yang digunakan (untuk penelitian ini, } \mathrm{n}=1) \\
\rho & =\text { beban trafik } \\
P W & =\text { peluang waktu tunggu seorang pelanggan (tertentu) }
\end{array}
$$

Sedangkan $P W$ diperoleh melalui persamaan 3.

$$
P W=\frac{\beta}{\alpha+\beta}
$$

dengan $\alpha$ dan $\beta$ dihitung menggunakan persamaan 4 , dan persamaan 5 .

$$
\begin{aligned}
& \alpha=\sum_{i=0}^{n-1} \frac{(n \rho)^{n}}{i !} \\
& \beta=\frac{(n \rho)^{n}}{n !(1-\rho)}
\end{aligned}
$$

Dengan demikian diperoleh hasil sebagai berikut:

- PW pada Prodi TP: 0,0892

- PW pada Prodi TM: 0,1890

- PW pada Prodi TI: 0,0685

- PW pada Prodi TF: 0,0685

- PW pada Prodi TE: 0,0892 
Untuk memperoleh nilai throughput digunakan persamaan 2.

A. Throughput aliran Internet Prodi TP

$$
\theta=\frac{10 \times 10^{6} \times 1(1-0,11)}{0,0892+1(1-0,11)}=9 \mathrm{Mbps}
$$

Kategori throughput

$$
\frac{9 \mathrm{Mbps}}{10 \mathrm{Mbps}} \times 100 \%=90 \% \Rightarrow \text { Bagus }
$$

Kategori loss

$$
\frac{(10-9) \mathrm{Mbps}}{10 \mathrm{Mbps}} \times 100 \%=10 \% \Rightarrow \text { Bagus }
$$

B. Throughput aliran Internet Prodi TM

$$
\theta=\frac{10 \times 10^{6} \times 1(1-0,37)}{0,1890+1(1-0,37)}=7,7 \text { Mbps }
$$

Kategori throughput

$$
\frac{7,7 \mathrm{Mbps}}{10 \mathrm{Mbps}} \times 100 \%=77 \% \Rightarrow \text { Bagus }
$$

Kategori loss

$$
\frac{(10-7,7) M b p s}{10 M b p s} \times 100 \%=23 \% \Rightarrow \text { Sedang }
$$

C. Throughput aliran Internet Prodi TI

$$
\theta=\frac{10 \times 10^{6} \times 1(1-0,08)}{0,0685+1(1-0,08)}=9,3 \mathrm{Mbps}
$$

Kategori throughput

$$
\frac{9,3 \mathrm{Mbps}}{10 \mathrm{Mbps}} \times 100 \%=93 \% \Rightarrow \text { Bagus }
$$

Kategori loss

$$
\frac{(10-9,3) \text { Mbps }}{10 M b p s} \times 100 \%=7 \% \Rightarrow \text { Bagus }
$$

D. Throughput aliran Internet Prodi TF

$$
\theta=\frac{10 \times 10^{6} \times 1(1-0,08)}{0,0685+1(1-0,08)}=9,3 \mathrm{Mbps}
$$

Kategori throughput

$$
\frac{9,3 \mathrm{Mbps}}{10 \mathrm{Mbps}} \times 100 \%=93 \% \Rightarrow \text { Bagus }
$$

Kategori loss

$$
\frac{(10-9,3) \text { Mbps }}{10 \text { Mbps }} \times 100 \%=7 \% \Rightarrow \text { Bagus }
$$

E. Throughput aliran Internet Prodi TE

$$
\theta=\frac{10 \times 10^{6} \times 1(1-0,11)}{0,0892+1(1-0,11)}=9 \mathrm{Mbps}
$$

Kategori throughput

$$
\frac{9 \mathrm{Mbps}}{10 \mathrm{Mbps}} \times 100 \%=90 \% \Rightarrow \text { Bagus }
$$

Kategori loss

$$
\frac{(10-9) \mathrm{Mbps}}{10 \mathrm{Mbps}} \times 100 \%=10 \% \Rightarrow \text { Bagus }
$$

\section{Penutup}




\subsection{Kesimpulan}

Dari analisis yang dilakukan, dapat diambil kesimpulan sebagai berikut :

1. Secara umum jaringan internet pada office STTA berada pada kategori baik.

2. Laju kedatangan tertinggi terdapat pada prodi TE sebesar 154 kbps sedangkan laju pelayanan tertinggi pada prodi TM sebesar 2,174Mbps.

3. Traffic Load tertinggi yaitu pada prodi TM sebesar 0,37 dan terkecil pada prodi TI dan TF sebesar 0,08.

4. Bandwidth yang dialokasikan untuk jaringan office STTA sebesar $10 \mathrm{Mbps.}$

5. Nilai throughput tertinggi sebesar 9,3 Mbps (93\%) dan nilai terendah sebesar 7,7 Mbps $(77 \%)$, berdasarkan tabel 4, kelima prodi dapat digolongkan kedalam kategori sangat baik.

6. Hasil perhitungan aliran loss didapatkan nilai tertinggi sebesar 23\%, sedangkan nilai terendah sebesar 7\%. Berdasarkan pada tabel 5, dapat disimpulkan bahwa aliran loss pada jaringan office STTA berada pada interval $16-25 \%$ yang berarti kategori sedang.

\subsection{Saran}

Adapun saran untuk pengembangan selanjutnya, sebagai berikut:

1. Perlu adanya penambahan lama waktu pengamatan dan jenis protokol lainnya,seperti protokol UDP.

2. Adanya aplikasi yang dapat mengelola dan menganalisis data trafik, agar dapat mempermudah pengambilan keputusan. 


\section{Daftar Pustaka}

[1] Cenggoro, Tjeng Wawan, and Ida Siahaan. "Dynamic Bandwidth Management Based on Traffic Prediction Using Deep Long Short Term Memory."Science in Information Technology (ICSITech), 2016 2nd International Conference on. IEEE, 2016.

[2] Wei, Yongtao, Jinkuan Wang, and Cuirong Wang. "A traffic prediction based bandwidth management algorithm of a future internet architecture." Intelligent Networks and Intelligent Systems (ICINIS), 2010 3rd International Conference on. IEEE, 2010.

[3] Astuti, Yenni, Daniel Teguh Rudianto, and Agga Prasetya. "Analisis Trafik Telekomunikasi Menggunakan Model Sistem Sharing." Conference SENATIK STT Adisutjipto Yogyakarta. Vol.2. 2016.

[4] Astuti, Yenni. "Analisis Throughput Trafik Data Menggunakan Model Sistem Sharing." Jurnal Teknologi 9.2 (2017): 124-131.

[5] Astuti, Yenni. "Teletrafik Sistem Berbagi Pada Aliran Internet." Prosiding Seminar Nasional ReTII. 2017.

[6] Pamungkas, Canggih Ajika "Manajemen Bandwith Menggunakan Mikrotik Routerboard di Politeknik Indonusa Surakarta" Jurnal INFORMA Politeknik Indonusa Surakarta Vol. 1 Nomor 3. 2016

[7] Haryadi, Sigit, 2012, Telletraffic Engineering Lecture Notes \& Handout \& Diktat Kuliah Rekayasa Trafik, Bandung.

[8] Prasetya, Agga "Analisis Kapasitas Sistem Terhadap Qos Pada Teletrafik Internet STTA Menggunakan Sistem Sharing” Teknik Elektro, STTA, 2016.

[9] Arifin, Yunus. "Implementasi Quality of Service dengan Metode HTB (Hierarchical Token Bucket) pada PT. Komunika Lima Duabelas." JELIKU-Jurnal Elektronik Ilmu Komputer Universitas Udayana 1.2 (2013): 1-7.

[10] Andrew S.Tanenbaum, "Computer Networks", 4th Edition, p88, Prentice Hall of India, 2003.

[11] Introduction to Teletraffic Theory, online, http://www.netlab.tkk.fi/apetus/s38145/k07/lectures.shtm, diakses terakhir pada 29 April 2017. 